\title{
Use of a Surgical Guide in a Crown- Lengthening Procedure to Improve the Aesthetics of the Interdental Papillae: A Case Report
}

\author{
Duygu Kılıç', Banu Arzu Alkan², Kerem Kılıç ${ }^{3}$ \\ ${ }^{1}$ Research Assistant, Department of Periodontology, Faculty of Dentistry, Erciyes University, Kayseri, TURKEY. \\ ${ }^{2}$ Associate Professor, Department of Periodontology, Faculty of Dentistry, Erciyes University, Kayseri, TURKEY. \\ ${ }^{3}$-Assistant Professor, Department of Prosthodontics, Faculty of Dentistry, Erciyes University, Kayseri, TURKEY.
}

\section{Key Words}

Surgical crown lengthening, surgical guide, anterior aesthetics

\section{Correspondence:}

Kerem Kılıç

Assistant Professor, Department of Prosthodontics, Faculty of Dentistry, Erciyes University, Kayseri, TURKEY Telephone: +90 (352) 4374937 e-mail: dtkeremkilic@hotmail.com

\begin{abstract}
Aim: This case report describes the use of a surgical guide in a crown-lengthening procedure to improve the aesthetics of the anterior interdental papillae in an adult female patient.

Methodology: A 40-year-old female underwent a crownlengthening procedure with guidance provided by a surgical template to correct unsatisfactory aesthetics in the anterior gingiva and prosthesis.

Results: The patient's functional and aesthetic expectations were met successfully with interdisciplinary treatment, including surgical crown lengthening and the placement of all-ceramic restorations.

Conclusions: This case showed that satisfactory anterior aesthetics can be achieved by comprehensive examination, careful planning of treatment employing a surgical guide, and prosthodontist-periodontist teamwork, even in the complete absence of interdental papillae.
\end{abstract}

(Int Dent Res 2012;2(3):75-80)

\section{Introduction}

The interdental papilla, which fills the space between two adjacent teeth, not only acts as a biological barrier in protecting periodontal structures, but also plays a critical role in aesthetics (1). Loss of the interdental papilla may cause functional, phonetic, and aesthetic problems. Several factors may contribute to the loss or absence of interdental papillae, which is characterized by the presence of "black triangles" following the placement of bridges, individual crowns, or restorative implants, particularly in the anterior region. The most common cause of this condition in the adult population is the loss of periodontal support due to plaque-associated lesions; other causes include abnormal tooth shape, inappropriate contours of prosthetic restorations, and traumatic oral hygiene procedures. Depending on size, these black triangles can have an extremely unaesthetic appearance that fails to meet the patient's aesthetic demands (2).

The average biological widths, or dimensions occupied by healthy gingival tissue above the alveolar bone, of junctional epithelium and connective tissue are 0.97 and $1.07 \mathrm{~mm}$, respectively (3). Crown lengthening includes the surgical removal of hard and soft tissues to gain supracrestal tooth length by lengthening the clinical crown and re-establishing the biological width. Indications for crown lengthening are caries below the gingival margin, fractured teeth with insufficient clinical crown exposure for fixed prosthodontics, 
teeth with excessive occlusal or incisal wear, and unaesthetic gingival architecture $(4,5)$.

When a crown-lengthening procedure involves many anterior teeth and marked alterations of gingival and bone levels, the use of a surgical guide is necessary to prevent over- or under-contouring of the bone and gingiva. Several investigators have reported the use of surgical guides in such procedures to demarcate the ultimate gingival margin level and create biological width (6-10).

This case report describes the use of a custommade surgical guide to facilitate a crownlengthening procedure, with the aim of improving the aesthetics of the anterior interdental papillae in an adult female patient.

\section{Case Report}

A 40-year-old female with full-mouth fixed partial dentures was referred to the Department of Periodontology, Dental Faculty, Erciyes University, Kayseri, Turkey, for the evaluation of unsatisfactory aesthetics in the anterior gingiva and prosthesis (Fig. 1A). She did not smoke and her medical history included no systemic disease. The patient complained of bleeding on brushing and gingival recession between several teeth. She indicated that her complaints had appeared following the placement of the bridge restoration, and she was unhappy about the "black triangles" between her maxillary anterior teeth. Examination revealed poorly contoured ceramometal restorations, gingival inflammation, and loss of interdental papillae. The existing restorations compromised the biological width of the periodontium, contributing to chronic inflammation. Clinical examination revealed a high lip line, which indicated that crown lengthening in the anterior teeth and premolars was required. Initial periodontal treatment consisting of scaling and root planing and oral hygiene instruction restored the patient's gingival health. Sounding to the bone level under local anesthesia and consultation with a prosthodontist led us to conclude that bone reduction was also necessary to achieve the desired positions of restoration margins. Thus, osseous resective crown-lengthening surgery was planned to extend labially from tooth 16 to tooth 27 , to maintain adequate biological width and minimize the "gummy" smile appearance while re-establishing the interdental papillae.
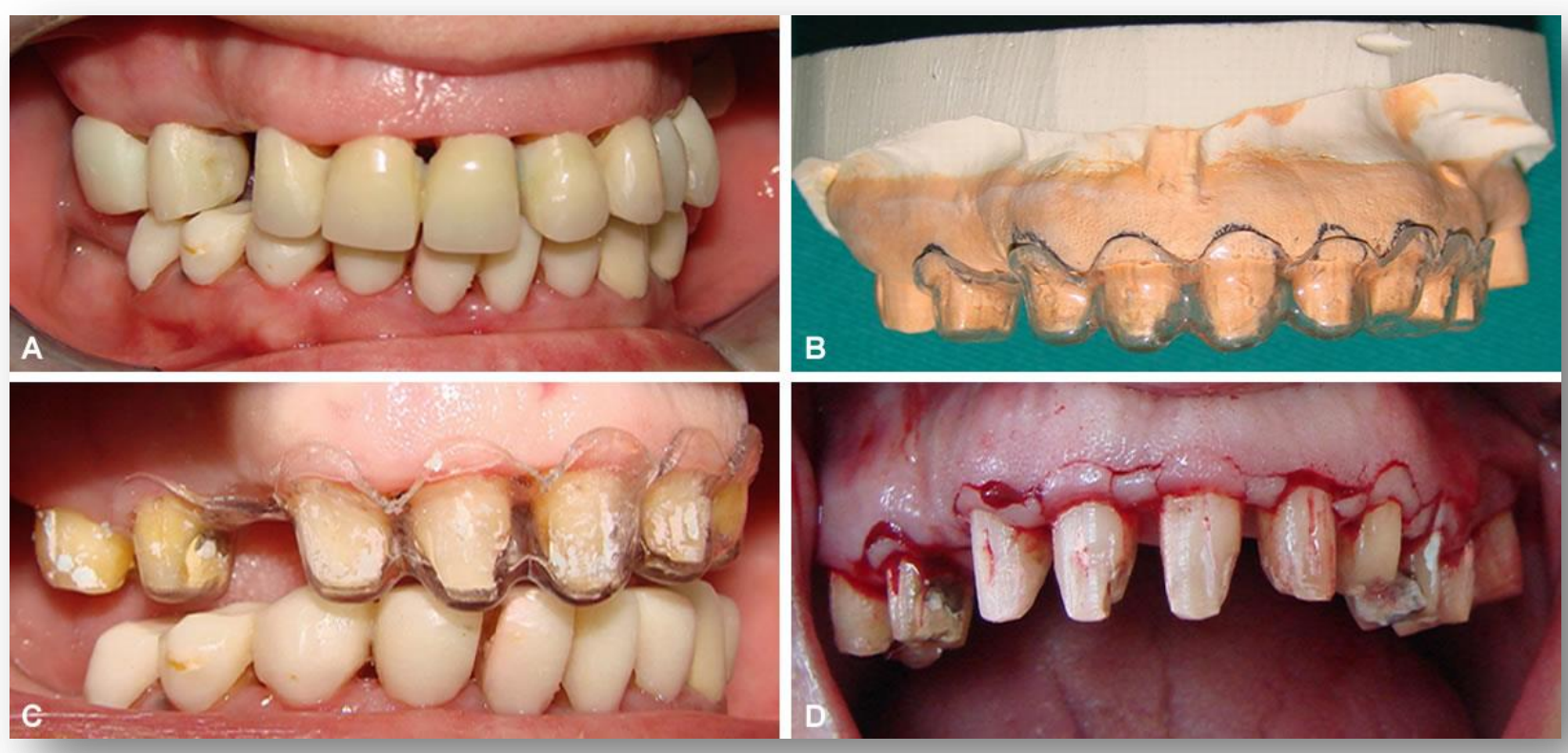

Figure 1. (A) The patient presented with unsatisfactory aesthetics in the anterior gingiva and prosthesis; (B) The surgical guide was constructed of thermoforming material; (C) The seating of the surgical guide in the patient's mouth was evaluated; (D) Vertical mini-incisions were made on the mesial and distal sides of each papilla. 
Before surgery, the prosthodontist determined the desired final position of the gingival margin relative to the lip line. All of the patient's clinical measurements were then transferred to a stone cast. The desired shape and level of the gingival margin were drawn on the cast, and a surgical guide was fabricated using transparent vacuum Essix $\AA$ thermoforming material. This material was extended from the proposed gingival margin to the palatal surfaces of the teeth, providing a definite seat for proper template positioning and stability (Fig. 1B). Then, the cast was duplicated and the predetermined lengthening distances were scraped off on the cast. Provisional crowns were constructed on this second cast.

Prior to surgery, the surgical guide was placed in the patient's mouth to confirm proper seating and to check whether the proposed level of the gingival margin met the aesthetic demands of both the prosthodontist and the patient (Fig. 1C). As an adequate zone of attached gingiva was available, allowing the placement of the initial incision to excise the desired amount of gingiva, we did not plan to use an apically positioned flap. Submarginal incisions were placed, taking into consideration the outlines of the surgical guide, to create new interdental papillae at teeth 16-27 without exposing the crestal portion of the interdental alveolar bone, thereby minimizing the likelihood of interdental gingival recession during healing. Then, vertical mini-incisions were made on the mesial and distal sides of each papilla to remove the gingiva on the labial aspect of each tooth (Figs. 1D and 2A). A fullthickness labial flap was reflected (Fig. 2B) and resective osseous surgery was performed using a round bur and back-action file to provide $3 \mathrm{~mm}$ of tooth structure beyond the final gingival margin level on the labial sides of the teeth. The surgical guide served as a reference point to measure the distance between the bone margin and the template, enabling the creation of an adequate zone for restoring biological width. The labial flap was then repositioned with reference to the surgical template and secured using an internal vertical mattress technique, which prevented depression of the papilla tips. Suture knots were placed on the palate to maximize the aesthetic appearance. A frenectomy was also performed to alleviate tension exerted by the buccal frenulum in the surgical area. Provisional crowns were then fixed to improve the adaptation of the papillary tissue to the embrasures during healing.
The patient was instructed not to brush the teeth in the surgical area, but to rinse with $0.12 \%$ chlorhexidine solution twice daily for $1 \mathrm{~min}$. She was prescribed an anti-inflammatory and analgesic (flurbiprofen, $100 \mathrm{mg}, 2 \times 1$ for 3 days) and an antibiotic (amoxicillin, $500 \mathrm{mg}, 3 \times 1$ for 8 days). The sutures were removed 1 week after surgery and healing was uneventful (Fig. 2C). Plaque was controlled with chlorhexidine rinsing in the surgically treated area for an additional 2 weeks, and the patient was then advised to begin mechanical cleaning with a soft-bristled toothbrush.

The patient was recalled for monitoring every 2 weeks in the first month and monthly thereafter for 6 months. She was referred to a prosthodontist after the tissues had healed completely.

The prosthetic treatment plan for this patient involved the placement of all-ceramic, full-mouth fixed restorations. The placement of single-unit allceramic crowns was planned for teeth $11,16,21-$ 24, 31-34 and 41-45, whereas teeth 12, 14, 25, and 27 would support three-unit all-ceramic fixed partial dentures in the right and left quadrants. Final preparation of the teeth began 6 months postoperatively because gingival recession can occur up to 6 months after surgery. The teeth were prepared using a circumferential chamfered margin configuration, and complete arch impressions were taken using vinyl polysiloxane (Elite H-D; Zhermack, Italy). The maxillomandibular relationship was also recorded using vinyl polysiloxane (BISICO; Bielefelder Dentalsilicone GmbH \& Co., KG, Postfach, Germany). After impressions had been taken, new provisional restorations were adapted and cemented on the prepared teeth with temporary cement (TNE; Temrex, Freeport, NY, USA). The casts and records were sent to the laboratory for the fabrication of allceramic veneers. The casts were mounted in an articulator (Hager \& Werken, Duisburg, Germany) and all-ceramic restorations were fabricated (Turkom-Cera; SDN-BHD, Kuala Lumpur, Malaysia). The final restorations were evaluated; adjusted to optimize contacts, contours, and aesthetics; and bonded with dual-polymerizing resin cement (Rely $X$ Unicem; 3M ESPE, Germany). The functional and aesthetic treatment outcomes satisfied the expectations of both the patient and the interdisciplinary team (Fig. 2D). The patient was motivated to maintain proper oral hygiene at annual recall appointments. 

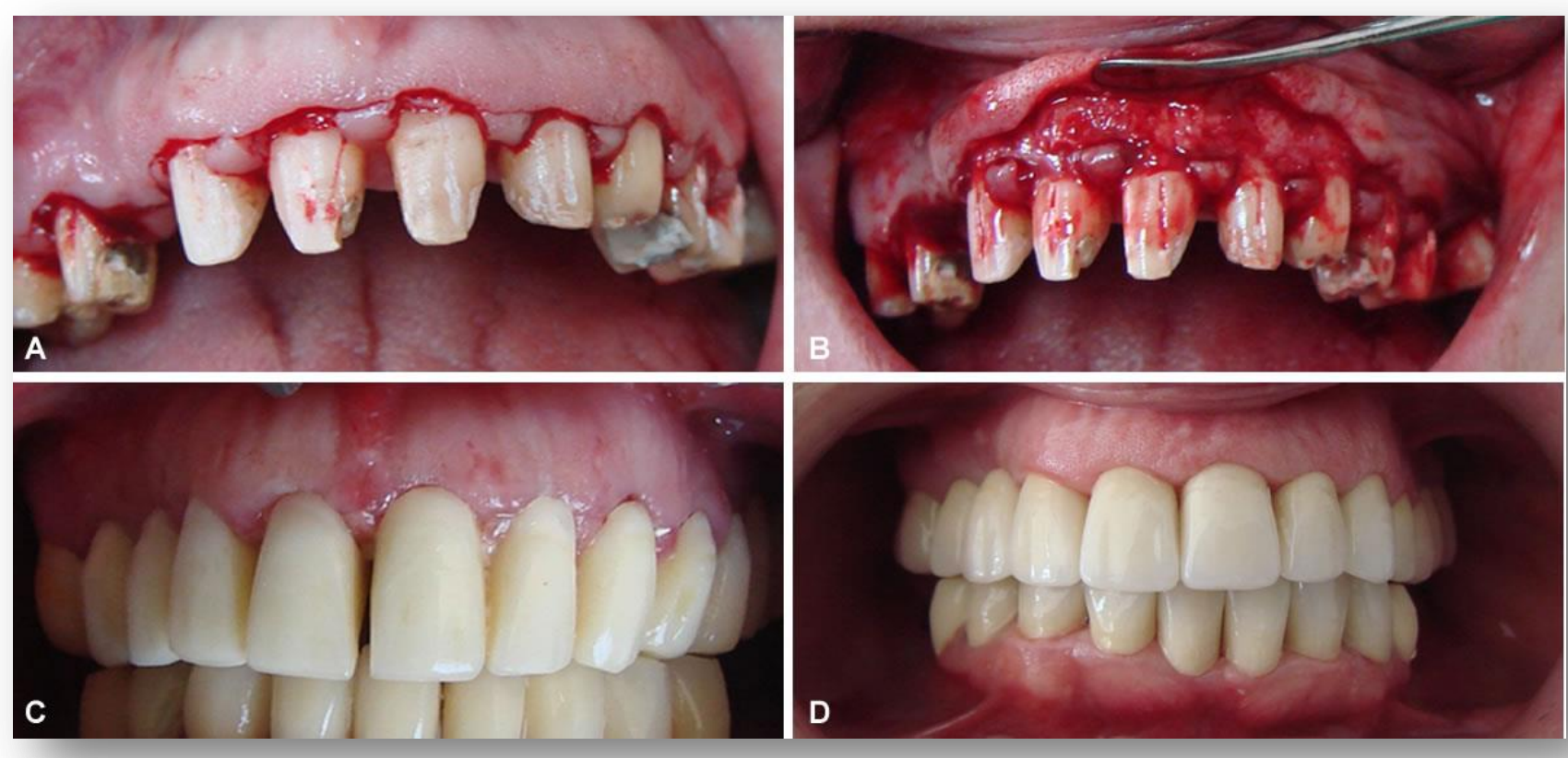

Figure 2. (A) The gingiva on the labial aspects of all teeth was removed; (B) A full-thickness labial flap was reflected; (C) The patient's condition 1 week postoperatively; (D) Final restoration.

\section{Discussion}

In recent years, aesthetic demands in dentistry have increased greatly because of the enhanced awareness of beauty. Clinicians have increasingly focused on the management and reconstruction of "pink aesthetics" in the hard and soft tissues surrounding teeth. The absence of interproximal papillae may cause devastating problems for patients (11). Clinicians in various disciplines have described several techniques for the restoration of missing papillae, but none of provides an excellent treatment outcome and clinical stability (12-14). The reconstruction of interdental papilla yields unpredictable results. Information on successful treatment outcomes is limited to case reports, and success is usually the result of a multidisciplinary team approach (15-19).

Many factors must be considered when surgical crown lengthening is contemplated, such as root forms and dimensions, positions of adjacent teeth, furcations, anatomic factors, gingival characteristics, and the proximity of roots. Prior to surgical crown lengthening, the restorative dentist can fabricate a surgical guide to facilitate the establishment of appropriate hard- and soft-tissue architecture. The surgical guide may assist analysis of limiting factors by the restorative team. Anatomic determinants, such as gingival architecture and consistency and supracrestal gingival tissue in specific areas, must be recorded preoperatively and may limit bone recontouring. The surgical template also guarantees the suturing of the flap in the proper position, so that its edge coincides with that of the template $(20,21)$.

In the present case, interdental papillae between teeth 16 and 27 had been lost due to the violation of biological width by the margins of the existing fixed prosthetic restoration. Our treatment goals were to reconstruct the interdental papillae using surgical crown lengthening and to restore biological width. Alternatively, this patient's problem could have been resolved by filling the black triangles with pink porcelain on the final prosthesis, but this would not have satisfied her aesthetic demands. Sounding to the bone level under local anesthesia revealed that bone reduction was also necessary to enable the proper positioning of restoration margins. We performed bone resection on only the labial aspects of the teeth, taking great care to adjust the level of the bone $3 \mathrm{~mm}$ away from the desired position of the gingival margin.

The original contour of the cementoenamel junction must be kept in mind when preparing teeth for full-coverage restorations, so that the resulting margin will be in harmony with the osseous architecture $(22,23)$. The margins on the mesial and distal aspects of the anterior teeth must be coronal to the labial and lingual aspects, with the magnitude 
of these differences depending on the patient's gingival morphotype (flat, scalloped, or pronounced scalloping). Failure to observe this principle will result in a barrel-shaped preparation with interproximal violation of the biological width, which may lead to inflammation, pocket formation, and attachment loss (24). In the present case, the prosthodontist determined the desired final position of the gingival margin and transferred it to the cast using the surgical guide for the construction of provisional crowns.

When full-coverage restorations are indicated, the avoidance of subgingival margin placement is preferable; however, margins in anterior areas frequently must be placed within the sulcus for aesthetic reasons. To minimize colonization of the sulcus by microorganisms associated with periodontitis, overhangs must be avoided and the original contours of the tooth must be reproduced as closely as possible (25). Margins should generally be placed no more than $0.5 \mathrm{~mm}$ subgingivally. In addition, proper embrasure space must be restored to promote periodontal health and an aesthetic appearance. The maturation of healing must be taken into consideration when planning restorative treatment following periodontal surgery. In areas where margins will be supragingival and tissue is reasonably thick, restorative treatment may be performed 2 months postoperatively, although the clinician must keep in mind that the gingival margin may migrate coronally during subsequent months. In areas where aesthetics are critical, a healing period of at least 6 months is recommended following periodontal surgery. The restoration margins should then be placed $0.5 \mathrm{~mm}$ subgingivally (26). In the present case, final restorations were constructed 6 months after periodontal surgery and margins were placed $0.5 \mathrm{~mm}$ subgingivally, in accordance with the findings of previous studies.

When the final restoration was inserted in the mouth, the anterior aesthetics satisfied the demands of both the patient and clinicians. Although the treatment of this patient yielded satisfactory results, controlled clinical studies are necessary to determine the predictability of the procedure.

\section{Acknowledgments}

The authors deny any conflicts of interest related to this study.

\section{References}

1. Reddy MS. Achieving gingival esthetics. J Am Dent Assoc 2003;134:295-304.

2. Kassab MM, Cohen RE. Treatment of gingival recession. J Am Dent Assoc 2002;133:1499-506.

3. Garguilo AW. Dimensions and relationships of the dentogingival junction in humans. J Periodontol 1961;32:261-7.

4. Lanning SK, Waldrop TC, Gunsolley JC, Maynard JG. Surgical crown lengthening: Evaluation of the biological width. J Periodontol 2003;74:468-74.

5. Walker $M$, Humen P. Template for surgical crown lengthening: Fabrication technique. J Prosthodont 1998; 7:265-7.

6. Claman L, Alfaro MA, Mercado A. An interdisciplinary approach for improved esthetic results in the anterior maxilla. J Prosthet Dent 2003;89:1-5.

7. Cortellini $\mathrm{P}$, Tonetti MS. Microsurgical approach to periodontal regeneration. Initial evaluation in a case cohort. J Periodontol 2001;72:559-69.

8. Lai JY, Silvestri L, Girard B. Anterior esthetic crown-lengthening surgery: A case report. J Can Dent Assoc 2001;67:600-3.

9. Robbins JW. Differential diagnosis and treatment of excess gingival display. Pract Periodontics Aesthet Dent 1999;11:265-72.

10. Shapiro A. Regeneration of interdental papilla using periodic curettage. Int J Periodontics Restorative Dent 1985;5:27-33.

11. Cardaropoli D, Re S, Corrente G, Abundo R. Reconstruction of the maxillary midline papilla following a combined orthodontic-periodontic treatment in adult periodontal patients. J Clin Periodontol 2004;31:79-84.

12. Azzi R, Etienne D, Carranza F. Surgical reconstruction of the interdental papilla. Int J Periodontics Restorative Dent 1988;18:467-74.

13. Beagle JR. Surgical reconstruction of the interdental papilla: case report. Int J Periodontics Restorative Dent 1992;12:145-51.

14. Han TJ, Takei HH. Progress in gingival papilla reconstruction. Periodontol 2000 1996;11:65-8.

15. Blatz MB, Hurzeler MB, Strub JR. Reconstruction of the lost interproximal papilla-presentation of surgical and non-surgical approaches. Int J Periodontics Restorative Dent 1999;19:395-406.

16. Cortellini $P$, Prato GP, Tonetti MS. The simplified papilla preservation flap. A novel surgical approach for the management of soft tissues in regenerative procedures. Int $\mathrm{J}$ Periodontics Restorative Dent 1999;19:589-99.

17. Kohl JT, Zander HA. Morphology of the interdental gingival tissues. Oral Surg Oral Med Oral Pathol1961;60:287-95.

18. Kokich VG. Esthetics: The orthodontic-periodontic restorative connection. Semin Orthod 1996;2:2130. 
19. Takei HH, Han TJ, Carranza FA Jr, Kenney EB, Lekovic V. Flap technique for periodontal bone implants: Papilla preservation technique. J Periodontol 1985;56:204-10.

20. Smukler H, Chaibi M. Periodontal and dental considerations in clinical crown extension: a rational basis for treatment. Int J Periodontics Restorative Dent 1997;17:464-77.

21. Jorgensen MG, Nowzari $H$. Aesthetic crown lengthening. Periodontol 2000 2001;27:45-58.

22. Ben-Yehouda A. Reconstruction of anterior papillae by interdental connective tissue grafts: a clinical report. J Prosthet Dent 1997;77:111-3.

23. Scutella F, Landi L, Stellino G, Morgano SM. Surgical template for crown lengthening: $A$ clinical report. J Prosthet Dent 1999;82:253-6.

24. Nevins M, Skurow HM. The intracrevicular restorative margin, the biologic width, and the maintenance of the gingival margin. Int J Periodontics Restorative Dent 1984;4:30-49.

25. Lang NP, Kiel RA, Anderhalden K. Clinical and microbiological effects of subgingival restorations with overhanging or clinically perfect margins. J Clin Periodontol 1983;10:563-78.

26. Bragger U, Lauchenauer D, Lang NP. Surgical lengthening of the clinical crown. J Clin Periodontol 1992;19:58-63. 